\title{
The Effects of Lactobacillus casei on Glycemic Response, Serum Sirtuin1 and Fetuin-A Levels in Patients with Type 2 Diabetes Mellitus: A Randomized Controlled Trial
}

\author{
Leila Khalili ${ }^{1}$, Beitullah Alipour ${ }^{2 *}$, Mohammad Asghari \\ Jafar-Abadi ${ }^{3}$, Ismail Faraji ${ }^{4}$, Tohid Hassanalilou ${ }^{1}$, Mehran Mesgari Abbasi ${ }^{5}$, \\ Elnaz Vaghef-Mehrabany ${ }^{6}$ and Mahmood Alizadeh Sani ${ }^{7}$
}

\begin{abstract}
${ }^{1}$ Department of Nutrition, Faculty of Nutrition and Food Sciences, Tabriz University of Medical Sciences, Tabriz, Iran; ${ }^{2}$ Department of Community Nutrition, Faculty of nutrition and food sciences, Tabriz University of Medical Sciences, Tabriz, Iran; ${ }^{3}$ Department of statistics and Epidemiology, Faculty of Health, Tabriz University of Medical Sciences, Tabriz, Iran; ${ }^{4}$ Internist, fellow of Endocrinology, Tabriz University of Medical Sciences, Tabriz, Iran; ${ }^{5}$ Drug Applied Research Center,Tabriz University of Medical Sciences, Tabriz, Iran; ${ }^{6}$ Department of Nutrition, Biochemistry and Diet Therapy, Faculty of nutrition and food science, Tabriz University of Medical Sciences, Tabriz, Iran; ${ }^{7}$ Department of Food Science and Technology, Faculty of nutrition and food sciences, Tabriz University of Medical Sciences, Tabriz, Iran
\end{abstract}

Received 23 December 2017; revised 15 January 2018; accepted February 2018

\begin{abstract}
Background: Type 2 diabetes mellitus (T2DM) is related to the gut microbiota with numerous molecular mechanisms. Modulating the gut microbiota by probiotics could be effective in management of T2DM. The aim of the present trial was to evaluate the effect of Lactobacillus casei on glycemic control and serum sirtuin1 (SIRT1) and fetuin-A in patients with T2DM. Methods: Forty patients with T2DM ( $\mathrm{n}=20$ for each group) were divided into intervention (probiotic) and placebo groups. The intervention group received a daily capsule containing $10^{8}$ cfu of L. casei for eight weeks. The patients in placebo group took capsules containing maltodextrin for the same time duration. Anthropometric measurements, dietary intake questionnaires, and blood samples were collected, and the patients were assessed by an endocrinologist at the beginning and at the end of the trial. Results: Fasting blood sugar, insulin concentration, and insulin resistance significantly decreased in probiotic group compared with placebo group $(-28.32$ [-50.23 to -6.41$], 0.013 ;-3.12$ [-5.90 to -0.35$], 0.028 ;-32.31$ [-55.09 to -9.54$], 0.007$, respectively). Moreover, $\mathrm{HbA1c}$ reduced after intervention, but the reduction was not significant $(-0.45$ [-0.96 to 0.05], 0.077). In comparison with placebo, the L. casei supplementation significantly increased SIRT1 and decreased fetuin-A levels at the end of the trial (0.52 [0.026 to 1.02], 0.040; -17.56 [-32.54 to -2.58$], 0.023$, respectively). Conclusion: $L$. casei supplementation affected SIRT1 and fetuin-A levels in a way that improved glycemic response in subjects with T2DM. Affecting the SIRT1 and fetuin-A levels introduces a new known mechanism of probiotic action in diabetes management. DOI: 10.29252/ibj.23.1.68
\end{abstract}

Keywords: Lactobacillus casei, Probiotics, Type 2 diabetes mellitus

Corresponding Author: Beitullah Alipour

Department of Community Nutrition, Faculty of Nutrition and Food Sciences, Tabriz University of Medical Sciences, Tabriz, Iran;

Tel.: (+98-413) 3357581; Fax: (+98-413) 3340634; E-mail: alipourb@tbzmed.ac.ir

\section{INTRODUCTION}

$\mathrm{T}$ ype 2 diabetes mellitus (T2DM), a metabolic disorder known by high blood glucose, is caused by the combination of not-sufficient secretion of insulin and insulin resistance ${ }^{[1,2]}$. Diabetes is among the top ten causes of death globally. This metabolic illness along with three other diseases (cardiovascular diseases, cancer, and respiratory diseases) accounts for over $80 \%$ of all premature non- 
communicable diseases deaths.

According to a recent report by International Diabetes Federation, 425 million adults suffer from diabetes, and 1 in 2 remains undiagnosed. The global prevalence of diabetes in adults of 20-79 years is now $7.3 \%(4.8-11.9 \%)$ that is estimated to reach $8.3 \%$ $(5.6 \%-13.9 \%)$ by $2045^{[3]}$. Evidence has shown that the intestinal microbiota could affect the host by influencing bile acid metabolism, body weight, proinflammatory status, and insulin resistance, as well as modulation of gut hormones. Moderating gut microbiota by the use of probiotics, prebiotics, and antibiotics could have beneficial effects on glucose metabolism and insulin resistance ${ }^{[4]}$. Probiotics, the live microorganisms, present health benefits to the host, especially when administered in sufficient amounts ${ }^{[5,6]}$. Physiologic functions of probiotics would lead to the modulation of gut microbiota and can affect appetite, food intake, body weight, and body metabolic functions through gastrointestinal pathways ${ }^{[7]}$.

Sirtuin1 (SIRT1), a nicotinamide adenine dinucleotide-dependent deacetylase, is a principal modulator of energy metabolism and exerts positive impacts on glucose homeostasis and insulin sensitivity. SIRT1 activators improve whole-body glucose homeostasis and insulin sensitivity in adipose tissue, skeletal muscle, and liver. Evidence has revealed that the endogenous activators of SIRT1 increase after calorie restriction and weight loss ${ }^{[8]}$.

Fetuin-A, a serum protein, is expressed and secreted by adipocytes and hepatocytes, and its level is upregulated in hepatic steatosis and other metabolic disorders $^{[9,10]}$. By binding the insulin receptor and inhibiting auto-phosphorylation of tyrosine kinase, fetuin-A could decrease insulin signaling in cell culture models $^{[11]}$. It has also been shown that fetuin-A concentration decreases by weight loss, indicating the reversibility of the increased fetuin-A level ${ }^{[12]}$. Thus, increasing the SIRT1 level and decreasing the fetuin-A level could be promising new therapeutic approaches for treating metabolic disorders such as T2DM. Considering the potential of probiotic bacteria, the aim of the present trial was to investigate the effects of Lactobacillus casei supplementation on the glycemic response and SIRT1 and fetuin-A levels in patients with T2DM.

\section{MATERIALS AND METHODS}

\section{Subjects}

An 8-week, parallel-group, randomized controlled trial was conducted in the Sheykholrayis Polyclinic of Tabriz University of Medical Sciences, Tabriz, Iran.
The recruitment process of participants began in September 2016, and the intervention was carried out in January 2017.

The target population of the present study was patients with T2DM. Subjects were contacted a day before commencing the supplementation, and the study was thoroughly explained to them. Volunteers were composed of 44 patients with T2DM, 30-50 years of age, and body mass index (BMI) lower than $35 \mathrm{~kg} / \mathrm{m}^{2}$. All patients had been diagnosed with T2DM for at least one year. Exclusion criteria were smoking, the presence of kidney, liver, and/or inflammatory intestinal disease, thyroid disorders, immunodeficiency diseases, required insulin injections, use of nutritional supplements within the previous three weeks of testing, use of estrogen or progesterone, pregnancy or breastfeeding, consuming any type of antibiotics, and consuming any other probiotic products within the previous two months of testing. Primary endpoints were the promotion of SIRT1, reduction of fetuin-A levels, and control of glycemic response, and secondary endpoint was the management of dietary intake and body weight.

The sample size for the current study was calculated on the basis of FBS results reported by Ostadrahimi et al. ${ }^{[13]}$ with a confidence level of $95 \%$ and a power of $80 \%$, which was found to be 18 patients. Taking into account the probable dropout of patients during the intervention course as well as the patients who may not adhere to the study protocol, 22 patients with T2DM were recruited for each group.

\section{Study design and measurements}

Of 44 patients who had met the inclusion criteria, 4 were excluded because of their unwillingness to participate in the study (Fig. 1). Subjects were randomly assigned to the probiotic $(n=20)$ and placebo $(n=20)$ groups, using a block randomization procedure with stratified subjects in each block based on sex and age. The allocation of the intervention or control group was concealed from the researchers, and the probiotic and placebo capsules had both an identical appearance and labeled information. Therefore, neither the subjects nor the investigators were aware of the treatment assignments in this double-blinded study. Over eight weeks, both groups consumed probiotic capsules containing $10^{8} \mathrm{cfu} L$. casei or placebo capsules. Considering the buffering capacity of the food on the survival of probiotic microbes during gastrointestinal transit ${ }^{[14]}$, the patients were asked to take the capsules with or just prior to a meal containing some fats. All patients were asked, throughout the 8-week trial, to maintain their usual dietary habits and lifestyle. The patients were 
instructed to keep the capsules under refrigeration and to avoid any changes in medication, if possible.

Arrangements were made so that the patients would receive the eight-week supply of their probiotic or placebo capsules at the beginning of the trial and were asked to take a capsule daily. Compliance with the capsule consumption guidelines was monitored by telephone interviews once a week. Information on demographic and anthropometric measurements and fasting blood samples were collected at the beginning and at the end of the trial. Nutrient intakes during three days were estimated using a 24-h dietary recall at the beginning, in the middle, and at the end of the study. Three-day averages of total energy intake (TEI) and macro-nutrients intake were analyzed by Nutritionist 4 software (First Databank, Hearst Corp, San Bruno, CA, USA). International Physical Activity Questionnaire (IPAQ) $)^{[15]}$ was completed for participants to assess physical activity level.

Anthropometric measurements were recorded by trained personnel. A blood sample was drawn from each patient after an overnight fasting. All whole blood and serum samples were collected and kept at $-70^{\circ} \mathrm{C}$ until assay. Blood samples were analyzed at the Drug Applied Research Center (Tabriz University of Medical Sciences, Tabriz, Iran).

Fasting blood glucose was measured using the standard enzymatic method with the Pars Azmun kit (Karaj, Iran). Glycated hemoglobin (HbA1c) in the whole blood was measured by cation exchange chromatography with the NycoCard HbA1c kit (Oslo, Norway). Insulin concentration was determined by a chemiluminescent immunoassay using a LIAISON analyzer (Diameter, Italy). To measure insulin resistance, we used insulin resistance index, HOMA-IR (homeostatic model assessment of insulin resistance), based on the following formula: HOMA1-IR = FPI $(\mathrm{mg} / \mathrm{dl}) \times$ FPG $(\mathrm{mg} / \mathrm{dl})) / 22.5$. Serum fetuin-A and SIRT1 concentrations were measured by human ELISA kits (Diameter, Italy and Bioassay Technology Laboratory, China).

The present study was conducted in accordance with the guidelines laid down in the Declaration of Helsinki, and all procedures were approved by the Ethics Committee of Tabriz University of Medical Sciences (no. IR.TBZMED.REC.1395.402). A written informed consent was obtained from each patient.

\section{Intervention procedure}

Hard yellow gelatin capsules were used as delivery vehicle in the present study. L. casei (Chr. Hansen, Denmark) was the active agent of the probiotic capsules, and maltodextrin was used as the excipient. The capsules were prepared using a capsule filling device under aseptic condition. To check the quality of probiotic capsules and ensure that an adequate dose of the probiotic was consumed by the experiment group (at least $10^{8} \mathrm{CFU} / \mathrm{day}$ ), a food technologist checked the bacterial count of the capsules at the baseline, in the middle and at the end of the trial period, by culturing the contents of three capsules at each. The capsules were cultured with the use of MRS agar (De Man, Rogosa, and Sharpe agar) via serial dilution and the pour plate technique. Bacterial enumeration of the capsules showed that the capsules were composed of a minimum of $10^{8}$ colony-forming units of $L$ c casei during the study period. The placebo capsules contained only maltodextrin. Since the bacterial count of the excipient could confound the outcomes of the study, the powder was cultured to ensure it was free of pathogens. Capsule count was performed by the researcher at the end of the study to evaluate compliance.

\section{Statistical analyses}

Statistical analysis was performed by SPSS software (ver. 17; SPSS Inc. IL, Chicago, USA). Normality of the numeric variables was checked by KolmogorovSmirnov test ${ }^{[16]}$. Data were presented using mean (SD), median (min-max) for the numeric normal, and nonnormal variables, respectively, as well as by the percentage of frequency for categorical variables. The between-group comparisons of baseline measures and demographic variables were conducted with independent $t$-test and/or Chi-square test where appropriate. For within-group comparisons, paired $t$ tests were used, where before and after intervention measurements were taken. To assess the effect of intervention, the analysis of covariance (ANCOVA) was used to control baseline measurements and confounders. In all analyses, $p$ values less than 0.05 were considered statistically as significant.

\section{RESULTS}

Forty patients with T2DM were recruited in the present clinical trial ( $\mathrm{n}=20$ for each group). Capsule bacterial counts showed a good compliance in those precipitants that completed the study, and no adverse effects were reported. There were no significant differences between the two groups with regard to any of the baseline characteristics (Table 1), biomedical parameters (Table 2), anthropometric measurements (Table 3), and dietary intake (Table 4) at the beginning of the study.

The effect of $L$. casei supplementation on biochemical parameters is shown in Table 2. After the 
Table 1. Characteristics and medication intake of the participants under study

\begin{tabular}{|c|c|c|c|}
\hline Variable & $\begin{array}{c}\text { Placebo group } \\
(\mathbf{n}=\mathbf{2 0})\end{array}$ & $\begin{array}{c}\text { Intervention group } \\
(\mathbf{n}=\mathbf{2 0})\end{array}$ & $\begin{array}{c}p \\
\text { value }\end{array}$ \\
\hline Age $\left(\right.$ Year) ${ }^{*}$ & $45.00(5.37)$ & $43.95(8.14)$ & 0.629 \\
\hline Diabetes Duration (Month) ${ }^{*}$ & $3.67(4.00)$ & $4.00(3.81)$ & 0.794 \\
\hline \multicolumn{4}{|l|}{$\operatorname{Sex}^{* *}$} \\
\hline Male & $7(35.0)$ & $7(35.0)$ & 1.00 \\
\hline Female & $13(65.0)$ & $13(65.0)$ & \\
\hline \multicolumn{4}{|l|}{ Marital status ${ }^{* *}$} \\
\hline Single & $2(10.0)$ & $2(10.0)$ & 1.00 \\
\hline Married & $18(90.0)$ & $18(90.0)$ & \\
\hline \multicolumn{4}{|l|}{ Education $^{* *}$} \\
\hline Primary & $0(0.0)$ & $1(5.0)$ & 1.00 \\
\hline Under diploma & $10(50.0)$ & $6(30.0)$ & \\
\hline Diploma & $5(25.0)$ & $11(50.0)$ & \\
\hline Higher education & $5(25.0)$ & $2(10.0)$ & \\
\hline \multicolumn{4}{|l|}{ Physical activity ${ }^{* *}$} \\
\hline Non-active & $10(50.0)$ & $5(25.0)$ & 0.247 \\
\hline Light-active & $8(40.0)$ & $11(55.0)$ & \\
\hline Active & $1(5.0)$ & $3(15.0)$ & \\
\hline Heavy-active & $1(5.0)$ & $1(5.0)$ & \\
\hline \multicolumn{4}{|l|}{ Diet Therapy (year) ${ }^{* *}$} \\
\hline Yes & $9(45.0)$ & $8(40.0)$ & 0.749 \\
\hline No & $11(55.0)$ & $12(60.0)$ & \\
\hline \multicolumn{4}{|l|}{ Glibenclamide $^{* *}$} \\
\hline Not used & $13(65.0)$ & $12(60.0)$ & 0.744 \\
\hline Using more than one/d & $7(35.0)$ & $8(40.0)$ & \\
\hline \multicolumn{4}{|l|}{ Metformin $^{* *}$} \\
\hline 1-2 tablet/d & $9(45.0)$ & $8(40.0)$ & 0.749 \\
\hline 3-4 tablet/d & $11(55.0)$ & $12(60.0)$ & \\
\hline
\end{tabular}

two-month intervention, FBS, serum insulin level, and HOMA.IR index significantly reduced in the intervention group $(p=0.002, p=0.035$, and $p=$ 0.001 , respectively). Moreover, the between-group differences for the mentioned glycemic response parameters were significant $(p=0.013, p=0.028$, and $p=0.007$, respectively). Evaluation of $\mathrm{HbA} 1 \mathrm{c}$ after two-month supplementation showed no significant reduction in probiotic group.

As presented in the Table 2, the level of SIRT1 significantly increased after two-month intervention in probiotic group $(p=0.006)$. Moreover, a significant decrease in the serum fetuin-A level was found in the probiotic group $(p=0.008)$. The between-group changes were statistically significant ( $p=0.040$ and $p=0.023$, respectively).

The effect of consumption of $L$. casei on anthropometric variables is shown in Table 3 . Consumption of $L$. casei for two months significantly decreased weight, BMI, and waist circumference in probiotic group compared with placebo group $(p<0.001, p<0.001$, and $p=0.029$, respectively). Moreover, the within-group changes for the three parameters were significant in probiotic group $(p<0.001, p=0.001$, and $p=$ 0.001 , respectively). Although the between-group change for waist to hip ratio was not significant, the within-group change was statistically significant ( $p$ $=0.001$ ).

The analysis of dietary questionnaires, shown in Table 4, revealed that TEI and the intake of macronutrients were significantly changed after probiotic supplementation. As indicated in Table 4, TEI and the intake of carbohydrate, fat, and protein significantly reduced during the intervention period in the intervention group $(p=0.003, p<0.001, p<$ 0.001 , and $p=0.001$, respectively). The betweengroup changes for TEI and protein were significant in $3^{\text {rd }}$ evaluation $(p=0.001$ and $p<0.001$, respectively); moreover, the between-group changes for carbohydrate and fat intake were significant in both $2^{\text {nd }}(p<0.001$ and $p=0.003$, respectively) and $3^{\text {rd }}(p=0.002$ and $p=0.009$, respectively) evaluation. 
Table 2. The Effect of L. casei supplementation on biochemical parameters

\begin{tabular}{|c|c|c|c|c|}
\hline Variable & $\begin{array}{l}\text { Placebo group } \\
\quad(\mathbf{n}=\mathbf{2 0})\end{array}$ & $\begin{array}{c}\text { Intervention group } \\
(\mathrm{n}=\mathbf{2 0})\end{array}$ & $\begin{array}{c}\text { MD } \\
(95 \% \mathrm{CI})\end{array}$ & $\begin{array}{c}P \\
\text { value }\end{array}$ \\
\hline \multicolumn{5}{|l|}{ FBS (mg/dl) } \\
\hline Before & $149.40(36.86)$ & $164.20(46.91)$ & $14.79(-12.21$ to 41.80$)$ & $0.274^{*}$ \\
\hline After & $150.59(36.72)$ & $135.84(43.01)$ & $-28.32(-50.23$ to -6.41$)$ & $0.013^{* *}$ \\
\hline MD $(95 \% \mathrm{CI}), p$ value & $1.18(-5.46$ to 7.83$), 0.71$ & $-28.35(-45.39$ to -11.31$), 0.002$ & & \\
\hline \multicolumn{5}{|l|}{ HbA1c $(\%)$} \\
\hline Before & $6.83(0.95)$ & $7.30(0.65)$ & $0.46(-0.05$ to 0.98$)$ & $0.081^{*}$ \\
\hline After & $7.13(0.99)$ & $6.84(0.99)$ & $-0.45(-0.96$ to 0.05$)$ & $0.077^{* *}$ \\
\hline MD $(95 \% \mathrm{CI}), p$ value & $0.08(-0.10$ to 0.26$), 0.379$ & $-0.24(-0.60$ to 0.12$), 0.190$ & & \\
\hline \multicolumn{5}{|l|}{ Insulin (mU/mL) } \\
\hline Before & $17.89(6.77)$ & $17.22(7.21)$ & $-0.67(-5.15$ to 3.81$)$ & $0.764^{*}$ \\
\hline After & $18.31(7.48)$ & $14.89(6.01)$ & $-3.12(-5.90$ to -0.35$)$ & $0.028^{* *}$ \\
\hline MD $(95 \% \mathrm{CI}), p$ value & $0.41(-0.28$ to 1.11$), 0.229$ & $-2.33(-4.48$ to -0.18$), 0.035$ & & \\
\hline \multicolumn{5}{|l|}{ HOMA.IR } \\
\hline Before & $117.03(46.84)$ & $123.14(44.82)$ & $6.11(-23.23$ to 35.46$)$ & $0.676^{*}$ \\
\hline After & $121.59(54.67)$ & $93.42(45.34)$ & $-32.31(-55.09$ to -9.54$)$ & $0.007^{* *}$ \\
\hline MD $(95 \% \mathrm{CI}), p$ value & $4.56(-2.29$ to 11.43$), 0.180$ & $-29.72(-45.62$ to -13.82$), 0.001$ & & \\
\hline \multicolumn{5}{|l|}{ SIRT1 (ng/mL) } \\
\hline Before & $5.87(2.17)$ & $6.04(1.51)$ & $0.16(-1.03$ to 1.36$)$ & $0.262^{*}$ \\
\hline After & $5.83(2.75)$ & $6.96(2.12)$ & $0.52(0.026$ to 1.02$)$ & $0.040^{* *}$ \\
\hline MD $(95 \% \mathrm{CI}), p$ value & $-0.04(-0.51$ to 0.43$), 0.862$ & $0.52(0.17$ to 0.87$), 0.006$ & & \\
\hline \multicolumn{5}{|l|}{ Fetuin-A $(\mu \mathrm{g} / \mathrm{ml})$} \\
\hline Before & $139.95(45.36)$ & $119.53(46.95)$ & $-20.41(-49.97$ to 9.14$)$ & $0.170^{*}$ \\
\hline After & $145.00(45.86)$ & $107.63(41.79)$ & $-17.56(-32.54$ to -2.58$)$ & $0.023^{* *}$ \\
\hline MD $(95 \% \mathrm{CI}) p$ value & $5.05(-2.59$ to 12.69$), 0.183$ & $-11.90(-20.29$ to -3.51$), 0.008$ & & \\
\hline
\end{tabular}

MD, mean difference; CI, confidence interval; FBS, fasting blood sugar; HbA1c, glycated hemoglobin; HOMA-IR, homeostatic model assessment of insulin resistance; SIRT1, Sirtuin1. Data are expressed as mean (SD). "For baseline between group comparisons, $p$ values are based on independent $t$-test; ${ }^{* *}$ After intervention between group comparisons, $p$ values and CI are based on analysis of covariance adjusted for baseline measures, BMI, energy intake, and drug intake. For within group comparisons, $p$ values and confidence intervals are based on paired $t$-test.

\section{DISCUSSION}

Controlling diabetes by natural food without side effects is a challenge for medical nutrition therapy of diabetes. This is the first study evaluating the effect of L. casei supplementation on serum SIRT1 and fetuin-A in patients with T2DM.

The outcomes of the present trial showed that eight weeks of $L$. casei supplementation improved glycemic response and increased SIRT1 and decreased fetuin-A level compared with placebo group. In comparison with placebo group, L. casei supplementation decreased the intake of total energy and macronutrients significantly; moreover, it improved anthropometric parameters in probiotic group.

Improvements in glycemic control by probiotic bacteria, as seen in this study, were in accordance with other similar studies conducted previously ${ }^{[17-20]}$. The antidiabetic property of Bifidobacteria and
Lactobacillus has been evaluated in human and animal studies $^{[19,21-23]}$. Previous studies have shown that probiotic treatment could reduce blood glucose concentration in diabetic status ${ }^{[21,24]}$. Ejtahed et al. ${ }^{[2]}$ have declared that probiotic yogurt, containing Lactobacillus acidophilus and Bifidobacterium lactis, decreased FBS and HbA1c in patients with T2DM. Ostadrahimi et $a l^{[13]}$ have shown that probiotic fermented milk, containing L. acidophilus, L. casei, and Bifidobacteria decreased fasting blood glucose and HbA1c compared with control group.

Several possible mechanisms of hypoglycemic effect of probiotics are discussed. Probiotics can affect gut bacteria to produce insulin-tropic polypeptides and GLP-1 (glucagon-like peptide-l), thus increasing glucose uptake by muscle and stimulating the liver absorption of blood glucose $\mathrm{e}^{[25]}$. The immunemodulatory and anti-inflammatory effects of probiotics and the modulation of intestinal microbiota composition are other possible mechanisms ${ }^{[2]}$. 
Table 3. The Effect of $L$. casei supplementation on anthropometric variables and blood pressure

\begin{tabular}{|c|c|c|c|c|}
\hline Variable & $\begin{array}{c}\text { placebo group } \\
(\mathbf{n}=\mathbf{2 0})\end{array}$ & $\begin{array}{c}\text { Intervention group } \\
(\mathbf{n}=\mathbf{2 0})\end{array}$ & $\begin{array}{c}\text { MD } \\
(95 \% \mathrm{CI})\end{array}$ & $\begin{array}{c}p \\
\text { value }\end{array}$ \\
\hline \multicolumn{5}{|l|}{ Weight (Kg) } \\
\hline Before & $83.45(15.84)$ & $77.15(13.58)$ & $-6.30(-15.74$ to 3.14$)$ & 0.185 \\
\hline After & $83.70(15.49)$ & $75.95(13.70)$ & $-1.52(-2.31$ to -0.76$)$ & $<0.001$ \\
\hline $\operatorname{MD}(95 \% \mathrm{CI}), p$ value & $0.25(-0.25$ to 0.75$), 0.309$ & $-1.20(-1.81$ to -0.58$), 0.001$ & & \\
\hline \multicolumn{5}{|l|}{ Waist circumference $(\mathrm{cm})$} \\
\hline Before & $102.90(10.22)$ & $97.50(8.94)$ & $-5.40(-11.54$ to 0.74$)$ & 0.083 \\
\hline After & $102.15(9.9)$ & $95.35(8.49)$ & $-1.77(-3.36$ to -0.18$)$ & 0.029 \\
\hline MD $(95 \% \mathrm{CI}), p$ value & $-0.75(-1.87$ to 0.37$), 0.179$ & -2.15 (3.30 to -0.99$), 0.001$ & & \\
\hline \multicolumn{5}{|l|}{ WHR } \\
\hline Before & $0.95(0.05)$ & $0.94(0.08)$ & $-0.01(-0.05$ to 0.03$)$ & 0.647 \\
\hline After & $0.94(0.06)$ & $0.92(0.07)$ & $-0.01(-0.02$ to 0.00$)$ & 0.052 \\
\hline $\mathrm{MD}(95 \% \mathrm{CI}), p$ value & $-0.006(-0.015$ to 0.003$), 0.18$ & $-0.020(-0.031$ to -0.009$), 0.001$ & & \\
\hline \multicolumn{5}{|l|}{ BMI $\left(\mathrm{kg} / \mathrm{m}^{2}\right)$} \\
\hline Before & $31.94(5.76)$ & $29.50(3.34)$ & $-2.43(-5.47$ to 0.60$)$ & 0.113 \\
\hline After & $32.19(5.49)$ & $29.02(3.36)$ & $-0.84(-1.26$ to -0.41$)$ & $<0.001$ \\
\hline $\mathrm{MD}(95 \% \mathrm{CI}), p$ value & 0.249 (-0.11 to 0.61$), 0.168$ & $-0.485(-0.73$ to -0.23$), 0.001$ & & \\
\hline \multicolumn{5}{|l|}{$\mathrm{SBP}(\mathrm{mmHg})$} \\
\hline Before & $114.50(5.10)$ & $114.00(5.02)$ & $-0.50(-3.74$ to 2.74$)$ & 0.757 \\
\hline After & $115.00(5.12)$ & $109.05(23.60)$ & $-5.27(-15.43$ to 4.89$)$ & 0.30 \\
\hline MD $(95 \% \mathrm{CI}), p$ value & 0.50 (-0.54 to 1.54$), 0.330$ & $-4.95(-15.31$ to 5.41$), 0.330$ & & \\
\hline \multicolumn{5}{|l|}{$\mathrm{DBP}(\mathrm{mmHg})$} \\
\hline Before & $66.50(4.89)$ & $70.00(6.48)$ & $3.50(-0.17$ to 7.17$)$ & 0.062 \\
\hline After & $68.00(6.15)$ & $67.00(4.70)$ & $-1.48(-3.97$ to 1.00$)$ & 0.235 \\
\hline MD $(95 \% \mathrm{CI}), p$ value & $0.50(-0.54$ to 1.54$), 0.330$ & $-2.00(-4.44$ to 0.44$), 0.104$ & & \\
\hline
\end{tabular}

$\mathrm{MD}$, mean difference; CI, confidence interval; WHR, waist to heap ratio; BMI, body mass index; SBP, systolic blood pressure; DBP, diastolic blood pressure. Data are expressed as mean (SD). For baseline between group comparisons, $p$ values are based on independent $t$-test. For after intervention between group comparisons, $p$ values and confidence intervals are based on analysis of covariance adjusted for baseline measures. For within group comparisons, $p$ values and confidence intervals are based on paired $t$-test.

HbA1c reduced after 2-month consumption of probiotic capsules; however, the reduction was not significant. Some of the similar studies have indicated that probiotics could reduce $\mathrm{HbA} 1 \mathrm{c}$ in patients with $\mathrm{T}_{2} \mathrm{DM}^{[2,13]}$. However in a meta-analysis of randomized, controlled trials, Li et al. ${ }^{[26]}$ have reported that there is no significant differences in $\mathrm{HbA1c}$ between the treatment and the control groups. The present study and most of the similar trials, evaluating the effect of probiotics on glycemic modulation in patients with T2DM, last for less than 3 months. A three-month period is needed to find the complete effect of the intervention on HbA1c.

The improved fasting insulin level found in this trial was in accord with the study conducted by Firouzi et $a{ }^{[27]}$ in which multi-strain probiotics significantly decreased the fasting insulin level in probiotics group after a 12-week intervention. The results of a metaanalysis, conducted by Yao et al. ${ }^{[28]}$, demonstrated that probiotics supplementation was associated with a significant reduction in fasting insulin level in patients with T2DM.

After eight-week intervention, the insulin resistance improved in probiotic group. The result was in accordance with other similar investigations ${ }^{[29,30]}$. Andreasen et $a l^{[19]}$ have revealed that consuming $L$. acidophilus NCFM for four weeks improved insulin sensitivity in comparison with placebo. Similarly, Kobyliak et $a l^{[31]}$ have found that supplementation with multi-probiotic for eight weeks is associated with a significant reduction of HOMA-IR. By reducing the oxidative stress and inflammatory response in diabetes, probiotics can improve insulin resistance ${ }^{[32]}$. Specific probiotic strains improve the function of intestinal barrier $^{[33]}$ and reduce the translocation of microorganisms and their derivatives ${ }^{[34]}$ to the systemic circulation, so reducing the pro-inflammatory cytokines production ${ }^{[35]}$. Studies have shown that special strains of lactic acid bacteria have antioxidant properties $^{[36,37]}$. The anti-oxidative mechanisms of probiotics could be assigned to reactive oxygen species scavenging, enzyme inhibition, metal ion chelation, and ascorbate autoxidation inhibition ${ }^{[37]}$. Therefore, it can be understood that by improving inflammation and oxidative stress, probiotics can improve insulin resistance in subjects with T2DM.

As the results shown in Table 1, the levels of SIRT1 and Fetuin-A were significantly affected by probiotic 
Table 4. The effect of $L$. casei supplementation on dietary intake

\begin{tabular}{|c|c|c|c|c|}
\hline Variable & $\begin{array}{l}\text { Placebo group } \\
(\mathbf{n}=\mathbf{2 0})\end{array}$ & $\begin{array}{c}\text { Intervention group } \\
(\mathbf{n}=\mathbf{2 0})\end{array}$ & $\begin{array}{c}\text { MD } \\
(95 \% \mathrm{CI}) \\
\end{array}$ & $\begin{array}{c}p \\
\text { value }\end{array}$ \\
\hline \multicolumn{5}{|c|}{ Total energy intake (Cal) } \\
\hline Before & $2131.62(368.83)$ & $2076.81(394.95)$ & $-54.32(-298.83$ to 190.29$)$ & 0.656 \\
\hline Mid & $2165.28(352.19)$ & $1954.62(405.71)$ & $-33.71(-68.48$ to 1.05$)$ & 0.057 \\
\hline After & $2147.85(387.22)$ & $1853.94(398.17)$ & $-35.80(-55.47$ to -16.13$)$ & 0.001 \\
\hline$p$ value & 0.080 & 0.003 & & \\
\hline \multicolumn{5}{|l|}{$\mathrm{CHO}(\mathrm{g})$} \\
\hline Before & $295.02(48.69)$ & $284.87(45.53)$ & $-10.15(-43.24$ to 22.94$)$ & 0.387 \\
\hline Mid & $297.79(48.42)$ & $282.00(53.68)$ & $-5.76(-7.81$ to -3.72$)$ & $<0.001$ \\
\hline After & $295.95(52.50)$ & $277.12(52.15)$ & $-8.67(-13.82$ to -3.52$)$ & 0.002 \\
\hline$p$ value & .310 & $<.001$ & & \\
\hline \multicolumn{5}{|l|}{ Protein (g) } \\
\hline Before & $79.91(13.83)$ & $77.68(14.87)$ & $-2.22(-11.41$ to 6.96$)$ & 0.627 \\
\hline Mid & $81.21(13.20)$ & $77.04(15.21)$ & $-1.08(-2.33$ to 0.16$)$ & 0.087 \\
\hline After & $80.71(14.31)$ & $75.89(14.93)$ & $-1.35(-1.89$ to -0.81$)$ & $<0.001$ \\
\hline$p$ value & 0.066 & 0.001 & & \\
\hline \multicolumn{5}{|l|}{ Fat (g) } \\
\hline Before & $71.03(12.29)$ & $69.00(13.23)$ & $-2.02(-10.20$ to 6.15$)$ & 0.619 \\
\hline Mid & $72.18(11.73)$ & $68.57(13.25)$ & $-1.64(-2.68$ to -.60$)$ & 0.003 \\
\hline After & $73.25(14.07)$ & $66.94(13.10)$ & $-4.29(-7.45$ to -1.13$)$ & 0.009 \\
\hline$p$ value & 0.248 & $<0.001$ & & \\
\hline
\end{tabular}

MD, mean difference; CI, confidence interval; CHO, carbohydrate. Data are expressed as Mean (SD). For baseline between group comparisons, $p$ values are based on independent $t$-test. For mid and after intervention between group comparisons, $p$ values and confidence intervals are based on analysis of covariance adjusted for baseline measures. For within group comparisons, $p$ values are based on repeated measure analysis of variance and Sidak post hoc tests.

consumption. The effect of probiotic supplementation on SIRT1 and/or fetuin-A was not evaluated in previous studies. Sirtuins, ubiquitous deacetylases, are metabolism regulators and energy homeostasis ${ }^{[38]}$. SIRT1 has a positive impact on metabolic disorders, including obesity, liver steatosis, and diabetes mellitus ${ }^{[39]}$. Due to its deacetylation activity, SIRT1 influences many steps of glucose metabolism in liver, pancreas, muscle, and adipose tissue and regulates insulin secretion ${ }^{[40,41]}$. It has been demonstrated that the SIRT1 expression in the adipose tissue of lean subjects is higher than that in obese individuals. According to previous investigations, it seems that weight loss associates with blood SIRT1 level changes. Mariani et $a l .{ }^{[38]}$ have found that there is a link between the reduction of body fat mass and increased plasma SIRT1; moreover, they showed that, in addition to the tissue levels, the circulating SIRT1 could be increased by a negative caloric balance. Calorie restriction has been reported to increase SIRT1 protein levels and activity in mice, rats, and humans. Moreover, it has been reported that SIRT1 gene variants are related to energy expenditure ${ }^{[42,43]}$.

Fetuin-A, a circulating glycoprotein that is secreted by the liver and adipose tissues, inhibits insulin receptor tyrosine kinase activity in animal studies ${ }^{[44]}$. Fetuin-A knockout mice have enhanced glucose sensitivity, resistance to weight gain, and lower serumfree fatty acid levels ${ }^{[45]}$. In humans, the liver-secreted fetuin-A is associated with atherosclerosis, insulin resistance, T2DM, and metabolic syndrome ${ }^{[46]}$. In a cross-sectional analysis, Ismail et al. ${ }^{[12]}$ have revealed that fetuin-A levels were higher in children and adults with obesity and metabolic syndrome. They reported that weight loss can reduce fetuin-A level. Haukeland et $a l^{[47]}$ have demonstrated that substantial weight loss in 21 children leads to a significant decrease in fetuinA concentrations. Brix et al. ${ }^{[48]}$ have reported that elevated fetuin-A levels in morbid obesity decreases after bariatric surgery. Additionally, caloric restriction is another factor that can decrease both fetuin-A levels and insulin resistance, as stated by Choi et al. ${ }^{[46]}$. They have found that caloric restriction significantly decreases expression and circulating levels of fetuin-A in overweight subjects with $\mathrm{T} 2 \mathrm{DM}^{[46]}$.

As stated in Table 3 and Table 4, energy intake and body weight significantly reduced after two months of L. casei supplementation in subjects with T2DM. 
Considering the effect of calorie restriction and weight loss on SIRT1 and fetuin-A levels, it can be understood that by reducing the appetite and dietary intake and body weight, probiotics could affect the plasma level of SIRT1 and fetuin-A in patients with T2DM in present trial.

L. casei supplementation for eight weeks significantly affected dietary intake and anthropometric indexes, including weight, BMI, and waist circumference in patients with T2DM. The effect of probiotics on gut microbial composition can affect appetite and food intake and also body composition and weight ${ }^{[4,7]}$. By modulating the gut microbiota, probiotics can affect the energy balance and/or metabolism of the host. Limited evidence exists on the effect of probiotic consumption on weight management in humans. The findings of present trial were similar to the study performed by Kadooka et al. ${ }^{[49]}$ in which they reported that a supplementation of fermented milk with Lactobacillus gasseri for three months induced a significant weight loss and a decrease in BMI, hip, and waist circumferences and body fat mass. Omar et al. ${ }^{[50]}$ have suggested that the consumption of Lactobacillus decreases total body fat mass.

A possible way for manipulating the mammalian eating behavior and body weight by probiotic bacteria is appetite-regulating hormones. Supplementation with VSL\#3, containing Lactobacillus strains, in mice reduced appetite-inducing hormones and neuropeptide $\mathrm{Y}$ in the hypothalamus ${ }^{[51,52]}$. Moreover, the levels of leptin, cholecystokinin, and other satiety peptides, regulating appetite and food intake through affecting vagus nerve signaling, were improved ${ }^{[53]}$. Probiotics can control metabolism and energy intake by the production of SCFAs (short chain fatty acids) through fermentation of indigestible polysaccharides ${ }^{[7]}$. SCFAs, produced by bacterial fermentation, can regulate satiety and food intake ${ }^{[54]}$. Through activating the $G$ proteincoupled receptors (GPR41 and GPR43) on intestinal epithelial cells, SCFAs stimulate GLP1 and peptide YY secretion ${ }^{[7]}$. Based on the results of present survey, probiotics affected patients' weight, BMI, and waist circumference by influencing dietary intake.

Taken together, this study demonstrates that $L$. case $i$ could improve glycemic response and SIRT1 and fetuin-A levels. Taking into account the metabolic impacts of SIRT1 and fetuin-A, management of their levels could be effective in diabetes control. The results of present trial help us to reveal a new mechanism of probiotics action in diabetes and its related metabolic disorders control. Besides, as shown in this study, the positive effects of probiotics on body weight could be translated into favorable metabolic effects and have beneficial effects on the homeostasis of glucose.

\section{ACKNOWLEDGEMENTS}

The authors are grateful to the financial support of the Vice Chancellor for Research of Tabriz University of Medical Sciences, Tabriz, Iran for performing this project.

CONFLICT OF INTEREST. None declared.

\section{REFERENCES}

1. Hassanalilou T, Payahoo L, Shahabi P, Abbasi MM, Jafar-abadi MA, Bishak YK, Khordadmehr M, Esnaashari S, Barzegar A. The protective effects of Morus nigra L. leaves on the kidney function tests and histological structures in streptozotocin-induced diabetic rats. Biomedical research 2017; 28(14): 6113-6118.

2. Ejtahed HS, Mohtadi-Nia J, Homayouni-Rad A, Niafar M, Asghari-Jafarabadi M, Mofid V. Probiotic yogurt improves antioxidant status in type 2 diabetic patients. Nutrition 2012; 28(5): 539-543.

3. International Diabetes Federation. The global picture. IDF Diabetes Atlas, 8th Edition edn., 2017.

4. Rad AH, Abbasalizadeh S, Vazifekhah S, Abbasalizadeh F, Hassanalilou T, Bastani P, Ejtahed HS, Soroush AR, Javadi M, Mortazavian AM, Khalili L. The future of diabetes mManagement by healthy probiotic microorganisms. Current diabetes revision 2017; 13(6): 582-589.

5. Homayouni A. Letter to the editor. Food chemistry 2009; 114(3):1073.

6. Bastani P, Akbarzadeh F, Homayouni A, Javadi M, Khalili L. Health benefits of probiotic consumption. Microbes in Food and Health. Germany: Springer; 2016.

7. Kobyliak N, Conte C, Cammarota G, Haley AP, Styriak I, Gaspar L, Fusek J, Rodrigo L, Kruzliak P. Probiotics in prevention and treatment of obesity: a critical view. Nutrition and metabolism (London) 2016; 13: 14.

8. Milne JC, Lambert PD, Schenk S, Carney DP, Smith JJ, Gagne DJ, Jin L, Boss O, Perni RB, Vu CB, Bemis JE, Xie R, Disch JS, Ng PY, Nunes JJ, Lynch AV, Yang H, Galonek H, Israelian K, Choy W, Iffland A, Lavu S, Medvedik O, Sinclair DA, Olefsky JM, Jirousek MR, Elliott PJ, Westphal CH. Small molecule activators of SIRT1 as therapeutics for the treatment of type 2 diabetes. Nature 2007; 450(7170): 712-716.

9. Stefan N, Fritsche A, Weikert C, Boeing H, Joost HG, Häring HU, Schulze MB. Plasma fetuin-A levels and the risk of type 2 diabetes. Diabetes 2008; 57(10): 27622767.

10. Ix JH, Shlipak MG, Brandenburg VM, Ali S, Ketteler M, Whooley MA. Association between human fetuin-A and the metabolic syndrome: data from the Heart and 
Soul Study. Circulation 2006; 113(14): 1760-1767.

11. Mathews ST, Chellam N, Srinivas PR, Cintron VJ, Leon MA, Goustin AS, Grunberger G. Alpha 2-HSG, a specific inhibitor of insulin receptor autophosphorylation, interacts with the insulin receptor. Molecular and cellular endocrinology 2000; 164(1): 87-98.

12. Ismail NA, Ragab S, El Dayem SMA, ElBaky AA, Salah N, Hamed M, Assal H, Koura H. Fetuin-A levels in obesity: differences in relation to metabolic syndrome and correlation with clinical and laboratory variables. Archives of medical sciences 2012; 8(5): 826-833.

13. Ostadrahimi A, Taghizadeh A, Mobasseri M, Farrin N, Payahoo L, Gheshlaghi ZB, Vahedjabbari M. Effect of probiotic fermented milk (kefir) on glycemic control and lipid profile in type 2 diabetic patients: a randomized double-blind placebo-controlled clinical trial. Iranian journal of public health 2015; 44(2): 228237.

14. Tompkins T, Mainville I, Arcand Y. The impact of meals on a probiotic during transit through a model of the human upper gastrointestinal tract. Beneficial microbes 2011; 2(4): 295-303.

15. Baghiani Moghaddam MH, Aghdam FB, Jafarabadi MA, Allahverdipour H, Nikookheslat SD, Safarpour S. The Iranian version of international physical activity questionnaire (IPAQ) in Iran: content and construct validity, factor structure, internal consistency and stability. World applied sciences journal 2012; 18(8): 1073-1080.

16. Asghari Jafarabadi M, Mohammadi S. Statistical series: introduction to statistical inference (Point estimation, confidence interval and hypothesis testing). Journal of diabetes and lipid disordetrs 2013; 12(3): 173-192.

17. Ejtahed HS, Mohtadi Nia J, Homayouni Rad A, Niafar M, Asghari Jafarabadi M, Mofid V. The effects of probiotic and conventional yoghurt on diabetes markers and insulin resistance in type 2 diabetic patients: a randomized controlled clinical trial. Iranian journal of endocrinology and metabolism 2011; 13(1): 1-8.

18. Asemi Z, Zare Z, Shakeri H, Sabihi SS, Esmaillzadeh A. Effect of multispecies probiotic supplements on metabolic profiles, hs-CRP, and oxidative stress in patients with type 2 diabetes. Annals of nutrition and metabolism 2013; 63(1-2): 1-9.

19. Andreasen AS, Larsen N, Pedersen-Skovsgaard T, Berg RM, Møller K, Svendsen KD, Jakobsen M, Pedersen BK. Effects of Lactobacillus acidophilus NCFM on insulin sensitivity and the systemic inflammatory response in human subjects. British journal of nutrition 2010; 104(12): 1831-1838.

20. Laitinen K, Poussa T, Isolauri E; Nutrition, Allergy, Mucosal Immunology and Intestinal Microbiota Group. Probiotics and dietary counselling contribute to glucose regulation during and after pregnancy: a randomised controlled trial. British journal of nutrition 2008; 101(11): 1679-1687.

21. Yun S, Park H, Kang J. Effect of Lactobacillus gasseri BNR17 on blood glucose levels and body weight in a mouse model of type 2 diabetes. Journal of applied microbiology 2009; 107(5): 1681-1686.
22. Moroti C, Souza Magri LF, de Rezende Costa M, Cavallini DC, Sivieri K. Effect of the consumption of a new symbiotic shake on glycemia and cholesterol levels in elderly people with type 2 diabetes mellitus. Lipids health disease 2012; 11(1): 29.

23. Yadav H, Jain S, Sinha P. Antidiabetic effect of probiotic dahi containing Lactobacillus acidophilus and Lactobacillus casei in high fructose fed rats. Nutrition 2007; 23(1): 62-68.

24. Lin CH, Lin CC, Shibu MA, Liu CS, Kuo CH, Tsai FJ, Tsai $\mathrm{CH}$, Hsieh $\mathrm{CH}$, Chen $\mathrm{YH}$, Huang CY. Oral Lactobacillus reuteri GMN-32 treatment reduces blood glucose concentrations and promotes cardiac function in rats with streptozotocin-induced diabetes mellitus. Brithish journal of nutrition 2014; 111(4): 598-605.

25. Al-Salami H, Butt G, Fawcett JP, Tucker IG, Golocorbin-Kon S, Mikov M. Probiotic treatment reduces blood glucose levels and increases systemic absorption of gliclazide in diabetic rats. European journal of drug metabolism and pharmacokinetics 2008; 33(2): 101-106.

26. Li C, Li X, Han H, Cui H, Peng M, Wang G, Wang Z. Effect of probiotics on metabolic profiles in type 2 diabetes mellitus: A meta-analysis of randomized, controlled trials. Medicine (Baltimore) 2016; 95(26): e4088.

27. Firouzi S, Majid HA, Ismail A, Kamaruddin NA, Barakatun-Nisak MY. Effect of multi-strain probiotics (multi-strain microbial cell preparation) on glycemic control and other diabetes-related outcomes in people with type 2 diabetes: a randomized controlled trial. European journal of nutrition 2016; 56(4): 1535-1550.

28. Yao K, Zeng L, He Q, Wang W, Lei J, Zou X. Effect of probiotics on glucose and lipid metabolism in Type 2 diabetes mellitus: A meta-analysis of 12 randomized controlled trials. Medical science monitor 2017; 23: 3044-3053.

29. Drucker DJ. The role of gut hormones in glucose homeostasis. Journal of clinical investigation 2007; 117(1): 24-32.

30. Zhang Q, Wu Y, Fei X. Effect of probiotics on glucose metabolism in patients with type 2 diabetes mellitus: a meta-analysis of randomized controlled trials. Medicina (Kaunas) 2016; 52(1): 28-34.

31. Kobyliak N, Kondratiuk K, Kyriienko D, Mykhalchyshyn G. Effect of alive probiotic on insulin resistance in type 2 diabetes patients: randomized clinical trial. Endocrine abstracts 2017; DOI: 10.1530/endoabs.49.OC2.4.

32. Lye HS, Kuan CY, Ewe JA, Fung WY, Liong MT. The improvement of hypertension by probiotics: effects on cholesterol, diabetes, renin, and phytoestrogens. International journal of molecular sciences 2009; 10(9): 3755-3775.

33. Madsen K, Cornish A, Soper P, McKaigney C, Jijon H, Yachimec C, Doyle J, Jewell L, De Simone C. Probiotic bacteria enhance murine and human intestinal epithelial barrier function. Gastroenterology 2001; 121(3): 580591.

34. Cani PD, Neyrinck A, Fava F, Knauf C, Burcelin RG, 
Tuohy K, Gibson GR, Delzenne NM. Selective increases of bifidobacteria in gut microflora improve high-fat-diet-induced diabetes in mice through a mechanism associated with endotoxaemia. Diabetologia 2007; 50(11): 2374-283.

35. Guha M, Mackman N. LPS induction of gene expression in human monocytes. Cell signal 2001; 13(2): 85-94.

36. Uskova M, Kravchenko L. Antioxidant properties of lactic acid bacteria--probiotic and yogurt strains. Voprosy pitaniia 2008; 78(2): 18-23.

37. Lin MY, Yen CL. Antioxidative ability of lactic acid bacteria. Journal of agriculture and food chemistry; 47(4): 1460-1466.

38. Mariani S, Fiore D, Persichetti A, Basciani S, Lubrano C, Poggiogalle E, GEnco A, Donini LM, Gnessi L. Circulating SIRT1 increases after intragastric balloon fat loss in obese patients. Obesity surgery 2016; 26(6): 1215-1220.

39. Herranz D, Serrano M. SIRT1: recent lessons from mouse models. Nature review cancer 2010; 10(12): 819823.

40. Turkmen K, Karagoz A, Kucuk A. Sirtuins as novel players in the pathogenesis of diabetes mellitus. World journal of diabetes 2014; 5(6): 894-900.

41. Chen D, Bruno J, Easlon E, Lin SJ, Cheng HL, Alt FW, Guarente L. Tissue-specific regulation of SIRT1 by calorie restriction. Genes and development 2008; 22(13): 1753-1757.

42. Lagouge M, Argmann C, Gerhart-Hines Z, Meziane H, Lerin C, Daussin F, Messadeq N, Milne J, Lambert P, Elliott P, Geny B, Laakso M, Puigserver P, Auwerx J . Resveratrol improves mitochondrial function and protects against metabolic disease by activating SIRT1 and PGC-1 $\alpha$. Cell 2006; 127(6): 1109-22.

43. Cantó C, Auwerx J. Caloric restriction, SIRT1 and longevity. Trends endocrinology and metabolism 2009; 20(7): 325-331.

44. Srinivas PR, Wagner AS, Reddy LV, Deutsch DD, Leon MA, Goustin AS, Grunberger G. Serum alpha 2-HSglycoprotein is an inhibitor of the human insulin receptor at the tyrosine kinase level. Molecular endocrinology 1993; 7(11): 1445-1455.

45. Mathews ST, Singh GP, Ranalletta M, Cintron VJ, Qiang X, Goustin AS, Jen KL, Charron MJ, JahnenDechent W, Grunberger G. Improved insulin sensitivity and resistance to weight gain in mice null for the Ahsg gene. Diabetes 2002; 51(8): 2450-2458.

46. Choi KM, Han KA, Ahn HJ, Lee SY, Hwang SY, Kim BH, Hong HC, Choi HY, Yang SJ, Yoo HJ, Baik SH, Choi DS, Min KW. The effects of caloric restriction on Fetuin-A and cardiovascular risk factors in rats and humans: a randomized controlled trial. Clinical endocrinology (Oxford) 2013; 79(3): 356-363.

47. Haukeland JW, Dahl TB, Yndestad A, Gladhaug IP, Løberg EM, Haaland T, Konopski Z, Wium C, Aasheim ET, Johansen OE, Aukrust P, Halvorsen B, Birkeland KI. Fetuin A in nonalcoholic fatty liver disease: in vivo and in vitro studies. European journal of endocrinology 2012; 166(3): 503-510.

48. Brix JM, Stingl H, Höllerl F, Schernthaner GH, Kopp HP, Schernthaner G. Elevated Fetuin-A concentrations in morbid obesity decrease after dramatic weight loss. Journal of clinical endocrinology and metabolism 2010; 95(11): 4877-4881.

49. Kadooka Y, Sato M, Imaizumi K, Ogawa A, Ikuyama K, Akai Y, Okano M, Kagoshima M, Tsuchilda T. Regulation of abdominal adiposity by probiotics (Lactobacillus gasseri SBT2055) in adults with obese tendencies in a randomized controlled trial. European journal of nutrition 2010; 64(6): 636-643.

50. Omar JM, Chan YM, Jones ML, Prakash S, Jones PJH. Lactobacillus fermentum and Lactobacillus amylovorus as probiotics alter body adiposity and gut microflora in healthy persons. Journal of functional foods 2013; 5(1): 116-123.

51. Yadav H, Lee JH, Lloyd J, Walter P, Rane SG. Beneficial metabolic effects of a probiotic via butyrateinduced GLP-1 hormone secretion. Journal of biological chemistry 2013; 288(35): 25088-25097.

52. Homayouni-Rad A, Soroush AR, Khalili L, NorouziPanahi L, Kasaie Z, Ejtahed HS. Diabetes management by probiotics: current knowledge and future pespective. International journal for vitamin and nutrition research 2017; 1(1): 1-13.

53. Duca FA, Swartz TD, Sakar Y, Covasa M. Increased oral detection, but decreased intestinal signaling for fats in mice lacking gut microbiota. PLoS one 2012; 7(6): e39748.

54. Shen J, Obin MS, Zhao L. The gut microbiota, obesity and insulin resistance. Molecular aspects of medicine 2013; 34(1): 39-58. 